\title{
Rede social e desempenho de programas de saúde: uma proposta investigativa
}

| ${ }^{1}$ Marcia Gomide, ${ }^{2}$ Michel Grossetti |

Resumo: Para alcançar a descentralização dos serviços de saúde no Brasil, tem sido necessário um grande esforço. Este implica essencialmente a construção de práticas inovadoras. Diversos pesquisadores têm enfrentado o desafio de produzir estudos para avaliar a implantação dos programas de saúde. Algumas pesquisas, em andamento atualmente, têm apontado as relaçôes interpessoais como responsáveis importantes que explicam os diferentes desfechos. Pretende-se neste artigo desenvolver uma discussão sobre a importância das relaçôes interpessoais na implementação de programas de saúde a partir do aporte da análise de redes sociais, propondo que as investigações voltadas à compreensão das flutuações de performances dos programas de saúde incorporem tal perspectiva.

> Palavras-chave: avaliação, programas de saúde, rede social, relações interpessoais.

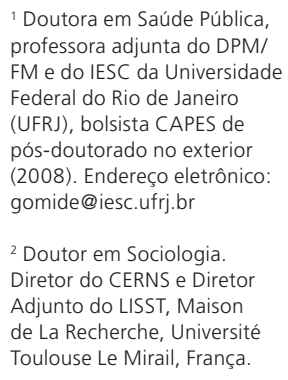

Recebido em: 13/05/2009. Aprovado em: 26/01/2010. 


\section{Introdução}

"Saúde para todos até o ano 2000" foi o lema da Conferência de Alma-Ata em 1978, na então União Soviética, marco histórico simbólico da dissociação entre a saúde, a medicina tecnológica e a cultura (LUZ, 2005), que impulsionou a criação do Sistema Único de Saúde - SUS (BRASIL, 1988).

Em sua VIII Conferência de Saúde, o SUS estabeleceu como princípios básicos: a universalidade, a equidade e a integralidade da assistência à saúde do indivíduo (BRASIL, 1990a). Com esses princípios, pretendeu garantir a atenção à saúde a qualquer cidadão (BRASIL, 1990b), desenvolvendo para tal os programas de saúde. O desempenho desses programas é importante fator para o processo de descentralização dos serviços de saúde no Brasil (ANDRADE, 2000; RAMOS JR. et al., 2006; BARBOSA et al., 2008), implicando essencialmente a construção de práticas inovadoras, considerando a gestão, o planejamento, o processo de trabalho e o usuário (STUFFLEBEAM, 2001; SANTOS et al., 2007).

Diversos pesquisadores têm enfrentado o desafio de produzir estudos para avaliar a implantação dos programas de saúde (ALMEIDA et al., 2003) e algumas pesquisas apontam as relaçóes interpessoais como responsáveis pelos diferentes desfechos dos programas de saúde (RAMOS JR et al., 2006; SANTOS et al., 2007; GOMIDE; GROSSETTI, 2008). Em outras palavras, tem-se observado a existência de uma corrente silenciosa e invisível, não considerada, mensurável, ou previsível, pelas atuais abordagens avaliativas. $\mathrm{O}$ objetivo deste artigo é propor que o "fenômeno" das relações interpessoais seja considerado na investigação de performance dos programas de saúde. Baseando-nos no instrumental da Análise de Redes Sociais, mas sem nos aprofundarmos em discussões teóricas, propomos aqui uma estratégia investigativa que seja capaz de contribuir com a identificação de tal fenômeno, de modo a dar suporte à tomada de decisões referentes à melhoria da qualidade dos programas de saúde.

\section{Redes e redes sociais}

\section{Esclarecimentos iniciais}

Tendo em vista que o termo rede é utilizado por diversos campos do conhecimento com as mais variadas interpretações, é importante apresentar alguns esclarecimentos iniciais. Os termos "redes sociais", "rede", "rede de organizaçoes", "redes de amigos", entre tantas outros, têm sido usado abusivamente há anos (VARANDA, 2007), 
nos diversos campos do saber e da prática. Nas áreas tecnológicas, são as redes do sistema de comunicação, ou de esgoto, de energia, por exemplo. Nas áreas assistenciais, são as redes como suporte a grupos específicos, tais como "redes de amigos do..." redes de suporte social, etc. $\mathrm{Na}$ área dos serviços e economia, o termo é aplicado desde grandes redes hoteleiras, como agências financeiras e assim por diante. No campo da educação, são as redes de escolas. $\mathrm{Na}$ área da saúde, vemos as redes públicas ou privadas, mas especificamente da saúde pública, o termo é utilizado pela organização do serviço, ou seja, rede de saúde, rede de serviço, redes de apoio, por exemplo. Importante notar que o termo "rede social" também tem sido usado para a designação de grupos de apoio. O que todos os exemplos têm em comum, além da utilização do termo "rede", é que estas redes são formais, pensadas, planejadas, organizadas, previstas, definidas e postas em prática conscientemente.

O termo "redes" que apresentamos no presente artigo tem uma conotação completamente diferente. Aqui, seguindo Varanda (2007, p. 208), a expressão "Análise de redes sociais" denota "um instrumento de análise social cujo potencial de sistematização e rigor é reconhecido há quase quatro décadas em todo o mundo e em variadíssimas disciplinas, da gestão à sociologia, passando pela geografia e a antropologia". O termo "rede" que empregamos aqui é diferente de todos os outros apontados nos exemplos acima. A análise de redes sociais em si é um instrumento indutivo da investigação social, cujo propósito é identificar os tipos de relações existentes entre os atores, medindo de forma sistemática o comportamento relacional desses atores. E medir tais relações, ou a troca de recursos, permite compreender as interdependências e assimetrias existentes em toda ação coletiva (VARANDA, 2007). Nestes termos, o que todas as demais "redes" têm em comum, ou seja, a ideia de estratégia organizacional sistêmica, é o que as diferencia da aplicação do termo "rede" aqui utilizado, que denota as relações existentes em determinado grupo e cuja conceituação básica será apresentada adiante.

\section{Contribuição da Teoria de Redes Sociais}

Conceito, definição e estruturas

A utilização do termo "rede social" tem evoluído ao longo de sua história (MERCKLE, 2004), sendo considerado como autor do termo o inglês John Barnes, no início dos anos 50. Porém foi o filósofo alemão Georg Simmel (18581918) que organizou sistematicamente as raízes da área. E em 1967, foi realizada 
pelo americano Stanley Milgram, a primeira tentativa empírica de demonstrar algumas destas proposições em sua famosa pesquisa sobre o "Pequeno Mundo". Na década seguinte, nos Estados Unidos, Harrison White (White et al., 1976) deu início à "escola" de análise das redes sociais, sendo seguido por Mark Granovetter, com sua famosa teoria sobre a força dos laços frágeis (GRANOVETTER, 1973). No campo da saúde, podemos destacar Carlos Sluzki, que faz escola trabalhando a rede social na prática sistêmica (Sluzki, 1899).

No Brasil, embora a produção científica a este respeito seja pouco desenvolvida, os estudos sobre redes têm apresentado abordagens analíticas (MARQUES 2006; ROSSONI et al., 2008) inovadoras. Por outro lado, importantes pesquisadores que problematizam o planejamento, tais como Gastão Campos, Emerson Merhy, Onocko Campos, para citar somente alguns, apesar de se reportarem diversas vezes a termos relacionados a "redes", utilizando-os com o sentido de estratégia organizativa formal, lançam algumas ideias que, mesmo não se enquadrando no arcabouço teórico-conceitual da análise de redes, têm relativa aproximação.

Entre estas, podemos destacar a ideia que Onocko Campos (2000) defende, de que os grupos de atores têm padrões de subjetividade e é da singularidade de cada componente que influencia o trabalho que se realiza. Argumenta, ainda, que as questões humanas e do mundo social não deveriam ser reduzidas ao mundo racional, propondo a não-separabilidade entre o agir racional e subjetividade. Em Campos (1994), encontramos esta mesma linha de proposição quando o autor "critica o planejamento" por não conseguir perceber que o social não é somente uma abstração estatística, indicando a necessidade de abertura para o campo subjetivo. Merhy (1997), por sua vez, considera inadequada a visão determinista e fechada do agir instrumental, pois a ação é um espaço de intervenção em um processo de intersubjetividades, é o lugar dos intercessores. Estes formam espaços próprios de gestão nos quais os distintos trabalhos se encontram como linhas de satisfação de necessidades. Este é um agir micropolítico existente nas relações do trabalho, o qual intervém pela sua capacidade de gerir, os processos de trabalho e os organizacionais.

Esses autores, entre outros, vão em direção a uma das principais premissas da análise de redes sociais, ao destacarem a importância da intersubjetividade nas relaçōes de trabalho, uma vez que são as relaçōes entre os atores o foco de interesse da análise de redes sociais e a base de tais premissas, permitindo quantificá-las e 
qualificá-las como fortes ou fracas, cooperação ou competição, centralizadas ou

descentralizadas, etc., possibilitando a detecção, por exemplo, do caráter mais ou menos hierárquico e/ou burocrático de uma organização a partir da detecção da intensidade da comunicação vertical (VARANDA, 2007). O balanço entre essas características indica, por exemplo, o grau de dependência de que uma organização formal pode ter em relação a seus atores. E quanto maior for esta dependência, mais frágil esta se torna. Campos e Amaral (2007) já avançam mais, quando propóem que a rede como organização de serviço gera dependência que se forma a partir de cada ator ou grupamento, sendo assim submetidos a uma autonomia relativa. Falta por enquanto, como apontam Onocko Campos (2000) e Campos (1997), expandir horizontes teóricos para além das fronteiras conhecidas pelo planejamento. E é com tal interesse que propomos apresentar algumas breves noções sobre a possibilidade de aplicação do instrumental teórico-metodológico da análise de redes sociais de modo a pensá-la como uma possibilidade, não fechada, como apontam Merhy et al. (1997), mas aberta e pronta a ser usada nas suas mais variadas correntes.

Hoje, em síntese, apesar da constituição de inúmeras linhas na análise de redes sociais, podemos dizer que rede social é o conjunto de atores sociais ligados entre si por relações interpessoais que permitam a transmissão de recursos, extrapolando os limites formais (DEGENNE; FORSE, 2004). Por relações formais, entendem-se aquelas declaradas publicamente, tais como organizações, associações, contratos de trabalho, dentre outras. No entanto, as relações ditas informais são aquelas particulares, ou pessoais (MERCKLE, 2004). Podem se distinguir em três formas básicas: (1) rede pessoal, (2) rede completa e, ainda, (3) cadeia relacional. A rede pessoal, ou entorno relacional, representa as relações diretas ou indiretas de uma pessoa. A rede completa apresenta as relações de um grupo social determinado (relações dentre membros de um clube esportivo, de uma profissão, por exemplo). A cadeia relacional busca mostrar a relação entre atores pelos seus intermediários (DEGENNE; FORSE, 2004).

As relações também podem ser de três tipos. Quando as cadeias de ligações (ou laços) são mais importantes em um senso que em outro, chama-se relação simétrica. Quando há similaridade de graus entre duas pessoas (mesmo nível de estudos, mesmo status social, mesma idade, etc.), denomina-se relação homofílica. As relações ditas polivalentes são aquelas nas quais uma mesma relação se investe 
de conteúdos diferentes ou se inscreve em contextos diversos, como por exemplo, alguém que conhece alguém porque trabalham na mesma empresa, e ainda são vizinhos e do mesmo partido político (DEGENNE; FORSE, 2004).

Uma rede pode ser pouco ou muito densa, dependendo do número de relações e da quantidade das ligações entre cada ator em relação a todos os componentes da rede. Nestas, quando se trata de rede completa, é possível observar a centralidade de um ator, que pode ser de três tipos: (1) centralidade de grau, quando a maioria das relações parte do ator; (2) centralidade de intermediação, quando a maioria dos caminhos passa sobre um ator; e (3) centralidade de proximidade, quando o ator é o mais próximo de todos os atores. Quando duas entidades são ligadas com elas mesmas, tem-se uma equivalência estrutural (DEGENNE; FORSE, 1994).

Mesmo que as discussões da área evoquem, em sua grande parte, a abordagem metodológica de análise da rede social mais do que as questôes conceituais, seguindo a lógica de Grossetti (2004), não faz sentido aumentar a lista de termos ou limitar o campo, pois os seguidores de diferentes correntes podem fazer suas "traduções" dos termos semelhantes. Autores clássicos (WHITE et al., 1976; GRANOVETTER, 1973; 1985), que discutem principalmente as formas de analise das redes sociais, também abordam pontos de vista teóricos às vezes diversos. Contudo, é preciso considerar que os diferentes modelos teóricos influenciam a análise das redes (EMIRBAYER; GOODWIN, 1994; EMIRBAYER, 1997). Entretanto, mais do que abordar questôes metodológicas relativas à análise da rede social e sua influência, importa aqui nos determos especialmente em alguns elementos essenciais advindos do resultado da análise das redes sociais.

\section{Rede social e relações interpessoais: outro enfoque}

Como apontado anteriormente, a noção de rede é utilizada na sociologia para designar um conjunto de relações entre pessoas ou entre grupos sociais. Mas há aqueles que focalizam como objeto de estudos os atributos individuais (sexo, idade, profissão etc. - atributos "tradicionais na saúde pública"). Outros focalizam não só estes atributos individuais, mas também as relaçôes e os padrões existentes entre eles, de modo a compreender como estas se formaram e se transformaram, analisando os efeitos das relações sobre o comportamento individual (MERCKLE, 2004) e sobre a transferência de conhecimentos (GROSSETTI, 2004). Estas 
relações diretas ou indiretas formam cadeias com extensões variáveis pertencentes aos grupos formais ou informais (GROSSETTI, 2004; MERCKLE, 2004).

A parcela de sociólogos que admite que os comportamentos ou as opiniōes dos indivíduos dependem das estruturas nas quais estão inseridos trata seus atributos estatisticamente e os considera independentes uns dos outros. Esta "postura" permite considerar que a estrutura da rede nada mais seria do que um conjunto de características dos indivíduos que compartilham dos mesmos atributos e, portanto, são estruturalmente próximos. Também permite dizer que o comportamento social é normativamente orientado. Assim, como os indivíduos são oriundos de uma mesma categoria compartilhando as mesmas normas interiorizadas, estas, as normas, seriam portanto as causas (DEGENNE; Forse, 2004).

Contudo, do ponto de vista da análise de redes sociais, as normas são os efeitos, e não as causas, de uma situação estrutural individual ou de grupos. A situação determina as oportunidades, as pressões e as alocações de recursos, explicando os padrões ou regularidades de comportamentos. São as relações entre os indivíduos que desenham esta estrutura normativa e explicam as diferenças de acessibilidade aos recursos. Ou seja, a norma é o efeito das forças coletivas conformando as contingências (DEGENNE; FORSE, 2004).

A história tem demonstrado o quanto as contingências influenciam os resultados; assim, é preciso encontrar a causa do evento (GROSSETTI, 2004) para compreendê-los. E para tal é essencial que o objeto de investigação seja a relação entre os elementos ligados (indivíduos, grupos, empresas, etc.) ou que sejam suscetíveis de ligação uns aos outros (DEGENNE; FORSE, 2004). Uma relação não é fechada em si mesma, pois não pode ser isolada de seu contexto estrutural. Sua função depende da posição estrutural que ocupa, portanto não é o somatório de relações que faz a estrutura, mas sim suas combinações, e estas exercem uma força em cada relação. Desta forma, cada novo elemento que se liga à rede vai proporcionar novos arranjos de relações redesenhando a rede. Este é um efeito que emerge das interaçōes (DEGENNE; FORSE, 2004).

Nestes termos, a ideia central é que os indivíduos estão em relações que condicionam de certa forma suas orientaçôes, suas possibilidades, seus comportamentos e, consequentemente, geram tipos de escolhas diversificadas (FERRAND; MOUNIER, 1998; FERRAND, 1997). Essa maneira de ver e se colocar e se relacionar na rede vai desencadear dois tipos gerais de processos de 
relacionamento: a découplage e o encastrement. Utilizamos aqui a definição de découplage como sendo um processo de autonomia (autonomisation) de uma entidade social em relação às outras entidades que reforça as especificidades e o encastrement como sendo o processo de aumento de dependência (GROSSETTI et al., 2006).

Estes opostos são dois processos em tensão permanente que mudam as formas sociais e os níveis de ação (GROSSETTI, 2004). A découplage tem, portanto, relação com a força de ligação das relações, pois uma das características de uma ligação forte é ser pouco substituível. Deste modo, a découplage pode ser medida pela capacidade do protagonista mudar na ausência do fator de ligação e pela capacidade da relação resistir. Entretanto, ao mesmo tempo em que uma ligação se forma e ocupa seu espaço, ou seja, se découple, ela está dentro da rede e, portanto, pode se tornar dependente - s'encastre. Os processos de encastrement e découplage modificam os recursos, os atores e as formas sociais e podem produzir situações irreversíveis (GROSSETTI, 2004).

As situações são a própria vida social, a qual é constituída de uma diversidade de processos de encastrement e de découplge localizados em níveis diferentes ao longo do tempo. Estes processos múltiplos podem advir de ritmos. Por exemplo, uma regularidade dentro de uma mudança constante ou uma transformação progressiva de formas sociais. E pode acontecer, portanto, que a dinâmica das formas sociais se faça mais ou menos bruscamente, mais ou menos caótica, levando ou não à ruptura ou à crise (GROSSETTI, 2004) dentro do processo de trabalho (GOMIDE; GROSSETTI, 2008).

\section{Rede social e saúde}

Os pesquisadores de ciências sociais trabalham no domínio da saúde utilizando o termo redes em duas abordagens diferentes. A primeira refere-se às redes de saúde que dá a estas uma forma organizacional, resultando em diversas experimentações, ou proposições, que estão sendo recentemente reguladas (CABÉ, 2005). Os pesquisadores se preocupam em analisar a forma na qual os indivíduos de determinado contexto se coordenam, constroem seus mundos comuns, se interrogam sobre a ideologia da organização da rede, sobre os problemas decorrentes da passagem dos indivíduos nas redes, mais do ponto de vista coletivo que individual (CRESSON et al., 2003). 
A segunda abordagem é a das redes sociais. Muitas pesquisas têm sido realizadas para avaliar o impacto do "suporte social", quer dizer, de relações sociais de ajuda, no que se refere à saúde ou bem estar (COHEN; SYME, 1985), por exemplo. O uso comum do termo "rede" instiga a aproximar as duas expressões "rede de saúde" e "rede social". Alguns autores já fizeram tal aproximação para estudar as relações entre as organizações de saúde utilizando métodos de análise de redes (CHANUT et al., 2005). Entretanto, a aproximação entre os dois termos não deveria ser pelo termo em si, mas pela lógica "prática-investigativa". Ela consiste em fazer a ligação da rede da organização com a rede de saúde e destas com as redes de indivíduos, pois que são eles que fazem funcionar as organizações. A ligação dos indivíduos formando estas relações é de grande importância, e esta importância aumenta uma vez que a organização adquire a forma desta rede de indivíduos. Situamo-nos, assim, na "dimensão do encastrement e da découplage das atividades organizacionais; na capacidade de autonomia possível, de robustez destas atividades que reportam a estas redes. É a recorrente problemática do encastrement e da découplage (GROSSETTI; BES, 2001) inerente aos processos de trabalho. Com esta abordagem, é possível avaliar em qual medida o nível das organizações é dependente das relações interpessoais e em quais condições ela pode se libertar de tal dependência.

Portanto, ao se mudar o foco do indivíduo dentro de um serviço ou programa de saúde, para as relações interpessoais destes indivíduos em um programa de controle, por exemplo, (CODEÇO; COELHO, 2008), é possível "desenhar" a rede pessoal responsável pela composição da rede organizacional. Não se trata de investigar o indivíduo pela esfera da atuação técnico-profissional, do processo de trabalho, ou pela esfera da satisfação do usuário, por exemplo. Não se trata de investigar opiniões ou percepções, conforme várias investigações avaliativas já vêm sendo desenvolvidas (LIMA et al., 2008; BARBOSA et al., 2008; NEMES et al., 2009, entre outros). Trata-se de abordar o universo das relações interpessoais entre os envolvidos. É preciso ir além da investigação do comportamento, das opiniōes e explicações dos indivíduos a respeito de seus contextos. Em lugar de pensar em dados empíricos e em atributos ou categorias, tais como jovens, homens, mulheres, nível econômico, é preciso pensar a realidade em termos de relações entre os atores (DEGENNE; FORSE, 2004). 

com atributos ditos similares e pertencentes a priori a população de estudo. Uma categoria pode pertencer a mais de uma realidade estrutural. Ou seja, a categoria médico pressupõe uma gama de atributos referentes à profissão, função e decisões pertinentes à estrutura em que a categoria "médico" se incluiu. Mas este médico é um individuo com um percurso pessoal e que em outro momento poderá exercer a função de gestor e não de médico dentro da mesma estrutura organizacional tais atributos e funçôes seriam distintos. E quais seriam as bases para sua tomada de decisões, seriam as mesmas, ou não?

A resposta a pergunta acima é: não. Como dito anteriormente, o conjunto das relações mudaria, pois que a adição de uma pessoa na rede de relações modifica as relações que vierem a surgir, redesenhando sua estrutura (DEGENNE; FORSE, 2004), e do comportamento que é associado à categoria e função em que se encontra o ator em relação ao conjunto de indivíduos do grupo (FREEMAN; DANCHING, 1997).

De volta à questão inicial: por que os programas têm performances e/ou desfechos diferentes? Um programa de saúde é composto por um conjunto de regras e metas a serem cumpridas dentro de uma estrutura lógica, normativa, hierárquica, com dimensões horizontais, dadas as especialidades profissionais que aí se incluem, verticais, dados os níveis gerenciais e "espaciais", dados os locais de trabalho pertinentes a cada categoria. São assim diversas as formas de um individuo se integrar e interagir na estrutura formal. Entretanto, toda estrutura formal, ou organizacional, é composta por pessoas que constroem suas relaçôes pessoais, as quais formam uma estrutura invisível, que é de rede social e suas relaçõos interpessoais.

Assim, como uma rede não é simplesmente o resultado do somatório das relaçôes (FORSÉ; LANGLOIS, 1997), quanto mais o indivíduo dentro da rede tem o controle sobre os recursos e as comunicações, mais central ele será, passando a ocupar um espaço de intermediação (intermediarité) (DEGENNE; FORSÉ, 2004). Cada ator dessa rede, antes de ser um profissional, é um indivíduo que, dentro se sua própria história singular, busca soluções para seus problemas na sua rede pessoal, a qual conforma a estrutura organizacional a partir de um processo contínuo de autonomia (découplage) e dependência (encastrement). 


\section{Uma proposta metodológica: a coleta, a construção e a análise dos dados}

Em verdade, não há nada de excepcionalmente novo na abordagem metodológica para a coleta e a construção dos dados necessários. O que difere, além do conteúdo das perguntas e da abordagem, é a maneira de se construir e analisar tais dados. Como instrumentos de coleta de dados, utilizam-se observações etnográficas e entrevistas a enquetes/questionários quantitativos. E a utilização destes está certamente sujeita ao problema que se pretende investigar. Em se tratando da construção de uma rede pessoal, por exemplo, é possível tanto uma abordagem quantitativa como qualitativa. No primeiro caso, um questionário detalhado pode ser elaborado de forma a desenhar as relações (FERRAND; MOUNIER, 1993). No segundo, é necessário reconstruir a história das relações interpessoais (DEGENNE; LEBEAUX, 1991; 1997), devendo-se utilizar a técnica do gerador de nomes. Ou seja, a partir das informações da pessoa entrevistada, que se pode chamar de informante-chave, ou name-eliciting, o qual deve ser definido considerando-se o limite do contexto operacional e a rede interpessoal (MARSDEN, 1987), se iniciará o percurso de novos informantes.

No caso de uma investigação que busca desenhar a rede social de uma organização, ou grupo, significa dizer que se pretende descrever a rede completa, cujas fronteiras, mesmo sendo socialmente instituídas (DEGENNE; FORSÉ, 2004; MERCKLE, 2004), são formadas pelas redes interpessoais, técnicas de entrevistas são mais recomendadas. "Rede completa" é a tradução literal do termo francês réseau complet como tradução aos termos ingleses whole networks ou total networks. Como a expressão francesa é utilizada com reservas (DEGENNE; FORSÉ, 2004), propõe-se aqui sua complementação com a palavra "coletiva" como alternativa para o melhor entendimento do termo em português.

Independentemente do tipo de rede que melhor explica o problema a ser investigado, a utilização de uma variedade de técnicas será fundamental para a construção dos dados (GROSSETTI, 2004). Histórias das relações aos bancos de dados e documentos das organizações, tanto quanto a realização de entrevistas e observações das relações interpessoais, são necessárias. O método da história de caso também é uma estratégia interessante, que permite investigar situações particulares, analisando o processo do qual esta resultou e 
identificando os tipos de relação que contribuíram na construção estrutural da situação (GROSSETTI et al., 2006).

Estas técnicas são bem conhecidas na Saúde Pública. O "pulo do gato" está na forma de elaboração das questões, tanto para as entrevistas quanto para os questionários. Por exemplo, em uma investigação que utiliza a técnica do "gerador de nomes" - que não deve ser confundida com a técnica da "bola de neve", pois esta é uma extensão da primeira (DEGENNE; FORSÉ, 2004), o objetivo é o entrevistado citar nomes de sua relação pessoal. É importante saber quem são as pessoas procuradas em suas tomadas de decisão, a quem ele se refere, se relaciona em momentos decisivos ou difíceis. Uma pergunta padrão pode ser: "com quem você fala quando precisa tomar uma decisão importante concernente ao seu trabalho?" ou "Com quem você discute sobre problemas pessoais importantes?" Os geradores de nomes podem ser abertos (para construção de redes pessoais) ou fechados, para a construção de redes completas/coletivas/globais (GROSSETTI, 2005).

Uma vez definido se a investigação seguirá a análise de rede pessoal ou completa/global, segue-se com etapas de natureza básica, porém estruturadas focando sempre a descrição e os tipos de relações. Começa-se em geral por entrevistar uma pessoa-chave (do programa) no momento da pesquisa, completando-se as informações com outras pessoas participantes do processo. Com a história suficientemente precisa, verificam-se os diversos níveis de ação, ou seja, os momentos de mobilização de recursos. A mobilização de recurso é a sequência de ações realizadas em busca da resolução de um problema. Elaborase a sequência das ações, descrevendo-se o processo e os comportamentos dos informantes (GROSSETTI et al., 2006).

As figuras 1 e 2 mostram, respectivamente, exemplos de uma rede pessoal e uma rede completa/coletiva que podem ser elaboradas a partir da conjugação das técnicas de entrevistas e de observação, no primeiro caso, e destas duas acrescidas da análise documental no segundo caso. Os traços indicam as relaçôes. Na figura 2 , as caixas indicam o pertencimento a uma estrutura organizacional formal. Por exemplo, a caixa maior, que engloba as duas caixas menores, seria a Secretaria Estadual de Saúde; a da esquerda, a Secretaria Municipal de Saúde, e a da direita, uma Unidade Básica de Saúde, na qual há uma equipe do Programa, ou Estratégia, de Saúde da Família. 

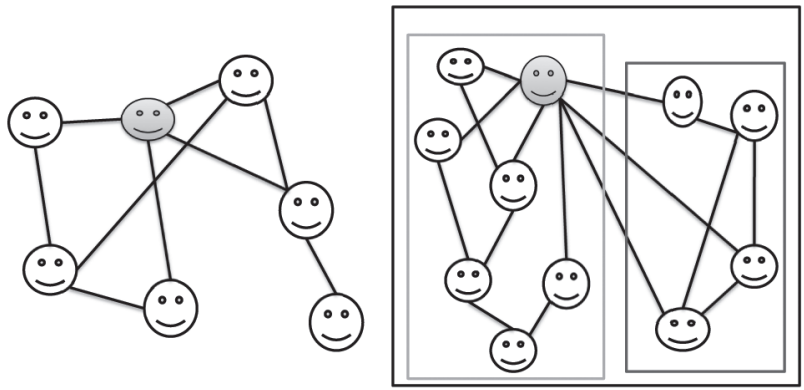

Uma vez desenhada a rede, é preciso analisá-la. A análise das redes é tema de discussão calorosa entre os sociólogos, pois abrange uma série de modelos teóricos. Autores clássicos como Harrisson White e Mark Granovetter (WHITE et al., 1976; GRANOVETTER, 1973; 1985), por exemplo, são ainda fonte para inspirações, reflexôes e discussões concernentes ao papel das categorizações de relações que formam a estrutura da rede social. Degenné e Forsé (1994), em primeira edição, e Degenné e Forsé (2004), em segunda edição, apresentam uma tentativa de síntese propondo um paradigma ao qual denominam de interacionismo estrutural, criticando a aproximação por categorias, valorizando as relaçôes e definindo a estrutura da rede como um efeito emergente da pressão (contrainte) existente.

Segundo Degenne e Forsé (2004), a análise da rede não é um fim em si mesmo. Ela é útil para mostrar como os fenômenos se dão. Neste aspecto, o debate entre "holismo" e "individualismo", "determinismo" e a "racionalidade" ganha espaço na análise de redes, como alicerces para diferentes teorias. Atualmente, ainda segundo os autores, a teoria mais difundida é a da "escolha racional". Segundo esta teoria, o indivíduo age de forma a alcançar seus objetivos que são fixados em função de suas preferências; age em função das pressões institucionais ou estruturais que interferem nas suas ações, influenciando as probabilidades de certas preferências serem atendidas. E assim, escolhem as ações que lhes permitem aproximar o máximo possível de suas preferências. Esta linha de pensamento leva aos princípios do "interacionismo estrutural", no qual a estrutura não se reduz à soma das ações individuais e a pressão exercida é somente formal dando livre arbítrio ao indivíduo, apesar de nem tudo ser possível. Com estas bases, o paradigma se decompõe nas seguintes premissas: (a) a estrutura pesa formalmente 
sobre a ação segundo um determinismo frágil; (b) a estrutura atinge a percepção dos interesses dos indivíduos; (c) as ações individuais obedecem ao princípio da racionalidade; e por fim, (d) a estrutura é o efeito emergente das interaçôes.

Considerando, portanto, o esquema hipotético apresentado na figura 1, supondo ser o indivíduo em cinza o informante-chave, na figura de um coordenador de programa, por exemplo, representa-se a estrutura de relaçóes pessoais deste coordenador. São ligações não sujeitas as formalidades da estrutura organizacional. Já na figura 2, o esquema indica as ligações dentro do contexto organizacional, incluindo-se ligações formais e pessoais. Imagine-se que os três indivíduos ligados à direita do "coordenador" na figura 1 são, na figura 2, alguns dos componentes da Unidade Básica de Saúde.

Ao se fazer a comparação entre os dois esquemas, é possível notar que as relações pessoais do coordenador incluem parte dos indivíduos da unidade básica, mas não todos, em oposição ao esquema da figura 2, em que aparecem as ligações oficiais, formais. Trata-se aqui de uma rede completa na qual poderia ser verificada a centralidade do coordenador, por exemplo, em relação a todos os indivíduos da rede formal. A maior ou menor centralidade, neste caso, implica uma capacidade de permuta de serviços e de informação, essenciais no desempenho do processo de trabalho e para a função de coordenador. Poder-se-ia considerar, a fim de melhor compreender, que a figura 2 representaria a rede completa/coletiva e que os laços pessoais e os formais estão representados. $\mathrm{O}$ coordenador pode não ter uma ligação direta com todos, mas indiretamente todos estão sob sua relação e isso é um fator importante para o cargo e a função que ocupa. Mas a forma de sua entrada na rede e o tipo de ligação pode fazer a diferença na performance de sua condução (OLIVIERI, 2007; RADOMSKY; SCHINEIDER, 2007).

A partir deste ponto, qualquer interpretação ou explicação do fenômeno apresentado no esquema das redes depende de quem são essas pessoas e quais são esses tipos de ligação. Uma ligação, seja ela profissional ou pessoal, pode ser considerada como forte ou frágil (GRANOVETTER, 1973). O autor define a força de um laço como uma combinação entre a quantidade de tempo, de intensidade emocional, de intimidade (confiança mútua) e de serviços recíprocos existentes em uma relação. $\mathrm{O}$ contrabalanço destes tipos de ligação acrescidos do contexto que ocupam os indivíduos e interesses vão conformar a estrutura da rede.

A confiança é uma das diversas formas de cooperação interindividuais que, em contraponto com oportunismo moderado, permitem o estabelecimento 
da cooperação (NEUVILLE, 1998). Como esta não corresponde à escolha de privilegiar um benefício coletivo a um ganho individual, ela é o agir em grupo com um objetivo em comum. E a realização de um objetivo implica uma interação entre diversos indivíduos (FORSÉ, 1997). Entretanto, estabelecer relação de confiança e cooperação depende da existência de um horizonte temporal entre as interações (NEUVILLE, 1998). Os dispositivos de coordenação, por exemplo, em um programa de saúde, são frágeis perante a pluralidade de comportamentos de ajuste, frente às assimetrias hierárquicas (BLIN, 2005) e a irregularidade temporal. A lógica de ajustes de conduta e de regulação da cooperação, por sua vez, relacionase a estrutura coletiva (BLIN, 2005) da rede como um espaço de ação coletiva.

Considerando-se que um programa de saúde depende da rede, do espaço coletivo e do tempo para estabelecimento das interaçóes, a rotatividade de figuras chave como a do coordenador e mesmo de outras categorias profissionais, torna frágil este espaço de troca, dependendo da capacidade de ajuste do grupo em superar as transformaçóes na estrutura da rede (GOMIDE et al., 2008). Se a capacidade do grupo for ainda dependente de um ou dois indivíduos centrais, mais frágil será a estrutura, frente à ausência destes.

Se supusermos, ainda, que o esquema represente à situação de um programa que não esteja alcançando as metas preconizadas pelo Ministério da Saúde, a interpretação da estrutura da rede e suas características, tais como existência de centralidade, processos de encastrement e découplage e tipos de laços existentes entre os indivíduos, permitiria verificar se o processo de trabalho flui como seria esperado. Permitiria verificar se a informação, ou ações, são "represadas" em determinado indivíduo, se há capacidade de resiliência dentro da estrutura da rede e se a confiança mútua é suficiente para permitir a troca de serviços recíprocos. Seria possível, então, identificar rupturas, ou inexistências de laços, que a depender de suas posições na rede poderiam tornar o fluxo do processo de trabalho inconstante, falho, ou insuficiente, resultando em um programa incapaz de atingir suas metas, explicando as flutuações de performance intra e interprogramas.

\section{Considerações finais}

Consideramos que a análise de redes sociais é um instrumento bastante adequado e suficientemente estruturado, capaz de auxiliar as incursóes avaliativas relacionadas aos serviços e programas de saúde. Sua capacidade para medir de forma sistemática 
o comportamento relacional dos atores, a troca de recursos, consequentemente as interdependências e a influência de uns sobre outros, identificando a estrutura do sistema social que permite, por sua vez, identificar as regularidades existentes na composição e no estabelecimento das relações (VARANDA, 2007), pode, em muito, viabilizar a explicação de resultados de performance de programas, como servir de base para planejamentos organizacionais. A distinção destes fenômenos possibilita, por exemplo, a identificação da centralidade de um ator dentro da rede. Sabemos que os indivíduos centrais estão mais bem informados, controlam mais as incertezas e têm mais informação sobre um maior número de pessoas de sua rede, o que reforça sua posição central dentro da rede (VARANDA, 2007), influenciando os resultados do grupo.

Lembrando que ter centralidade não é sinônimo de ter um cargo central formal - chefia, gerencia etc. (GOMIDE; GROSSETTI, 2008) -, a identificação de atores centrais pode ser um resultado importante na explicação de assimetrias de resultados entre os programas, por exemplo. E como já defendia Granovetter (1985), investimentos nas relações de trabalho são fundamentais para a obtenção de resultados ótimos.

Longe de pretender, neste espaço, cobrir todo o conhecimento existente sobre análise de redes sociais, tanto quanto de abranger todos os aspectos envolvidos na utilização destes conhecimentos no auxílio à avaliação de programas de saúde, e sim com o intuito de aguçar o interesse dos investigadores da área, notadamente aos da gestão e planejamento e avaliação, para tal alternativa, é que apresentamos estas ideias mais propositivas que conclusivas. $\mathrm{Na}$ base de tudo estão os indivíduos e seus objetivos. E onde há indivíduos, há relações interpessoais e estas conformam as redes que se traduzem em ações, fazendo "emergir" os diferentes resultados alcançados pelos programas.

\section{Agradecimentos}

À Coordenação de Aperfeiçoamento Pessoal - CAPES, pela bolsa de PósDoutorado no Exterior à autora, Processo número 4385-07-1. Ao supervisor do estágio pós-doutoral, Dr. Michel Grossetti, pesquisador da Université Toulouse Le Mirail, por seus ensinamentos e sua dedicada atenção. 
ALMEIDA C. et al. PRO-ADESS: Projeto desenvolvimento de metodologia de avaliação do desempenho do sistema de saúde brasileiro. Relatório Final. Rio de Janeiro: CICT-FIOCRUZ, 2003. 258p.

ANDRADE, V.L.G. A descentralização das atividades e a delegação das responsabilidades pela eliminação da Hanseníase ao nível municipal. Boletim de Pneumologia Sanitária, Rio de Janeiro, v. 8, n. 1, p. 47-51. 2000.

BARBOSA, J.C. et al. Olhares sobre as ações do programa de controle da hanseníase: a perspectiva dos profissionais de saúde no Brasil. Cad. Saúde Coletiva, Rio de Janeiro, v. 16, n. 2, p. 273-292, 2008.

BLIN, T. Ressources, stratégies et régulation d'un espace d'action colletive: la cas des «refugiés» de Saint-Ambroise. L’Année Sociologique, v. 55, n. 1, p. 171-196, 2005.

BRASIL. Constituição Federal de 1988. Título VIII, Capítulo II, Seção II (arts. 196 a 200). Brasília, 1988.

. Ministério da Saúde. Lei 8080 / 90. Brasília, 1990a.

. Ministério da Saúde. ABC do SUS - Doutrinas e Princípios. Brasília, 1990b.10p.

. Ministério da Saúde. Secretaria de Vigilância de Saúde. Plano Nacional de Monitoramento e Avaliação. Programa Nacional de DST/AIDS. Brasília: Ministério da Saúde, 2005.

CABÉ, M.-H. La santé en réseaux, quelles innovations? Sociologies Pratiques, Paris, v. 2, n. 11, p. 1-4, 2005.

CAMPOS, R.O. Planejamento e razão instrumental: uma análise da produção teórica sobre planejamento estratégico em saúde, nos anos noventa, no Brasil. Cadernos de Saúde Pública, Rio de Janeiro, v. 16, n. 3, p. 723-731, 2000.

CAMPOS, G.W. Consideraçôes sobre a arte e a ciência da mudança: Revolução das coisas e reforma das pessoas. O caso da saúde. In: CECILIO, L.C.O. (Org.). Inventando a mudança na saúde. São Paulo: Editora Hucitec, 1994. P. 29-88.

CAMPOS, G.W.S.; AMARAL, M.A. A clínica ampliada e compartilhada, a gestão democrática e redes de atenção como referenciais teórico-operacionais para a reforma do hospital. Ciência e Saúde Coletiva, v. 12, n. 4, p. 849-859, 2007.

CHANUT, C. et al. L'analyse des réseaux sociaux appliquée au système de santé. Santé Publique, Paris, v. 17, n. 3, p. 403-441, 2005.

CODEÇO, C.T., COELHO, F.C. Redes: um olhar sistêmico para a epidemiologia de doenças transmissiveis. Ciência \& Saúde Coletiva, Rio de Janeiro, v. 13, n. 6, p. 1767-1774, 2008.

COHEN, S.; SYME, L. Social support and health. San Francisco: Academic Press, 1985. 390p. 
CRESSON, G.; DRULHE, M.; SCHWEYER, F.-X. Coopérations, conflits et concurrences dans le système de santé. Rio de Janeiro: ENSP, 2003. 288p.

DEGENNE A.; FORSÉ M. Les réseaux sociaux: une analyse structurale en sociologie. Paris: Henri Mendras, 1994. 288p (Colletction U, Série Sociologie).

DEGENNE, A.; LEBEAUX, M-O. L'entraide entre les ménages: un facteur d'inégalité sociale? Sociétés Contemporaines, Paris, v. 8, p. 21-42, 1991.

. Qui aide qui, pour quoi? L'année SOCIOLOGIQUE, Paris, v. 47, n. 1, p. $117-$ $142,1997$.

DEGENNE, A.; FORSE, M. Les Réseaux Sociaux. Paris: Armand Colin, 2004. 295p.

EMIRBAYER, M.; GOODWIN, J. Network analysis, culture, and the problems of agency. The American Journal of Sociology, v. 99, p. 1411-1454, 1994.

EMIRBAYER, M. Manifesto for relational sociology. The American Journal of Sociology, v. 103, p. 281-317, 1997.

FERRAND, A.; MOUNIER, L. Influence des reseaux de conference sur les relations sexuelles. In: BAJOS N. et al. La sexualité aus temps du sida. Paris: PUF, 1998. p. 255-304.

L'échange de paroles sur la sexualité: une analyse des relations de confidence. Population, v. 5, p. 1451-1476, 1993.

FERRAND, A. La structure des systèmes de relations. L'année Sociologique, v. 47, n. 1, p. 37-54, 1997.

FORSE, M. Capital social et emploi. L’Année Sociologique, v. 47, n. 1, p. 143-181, 1997.

FORSÉ, M.; LANGLOIS, S. Présentation: réseaux, structures et rationalité. L'Année Sociologique, v. 47, n. 1, p. 27-35, 1997.

FREEMAN LINTON, C.; DANCHING, R. An international comparative study of interpersonal behavior and role relationships. L’Année Sociologique, v. 47, n. 1, p. 89-115, 1997.

GOMIDE, M.; GROSSETTI, M. Crise au dispensaire: réseaux sociaux et fonctionnement d'un dispensaire au Brésil. Revue Sociologie Santé, v. 28, p. 71-88, 2008.

GRANOVETTER, M. Economic action and social structure: the problem of embedded ness. The American Journal of Sociology, v. 95, n. 5, p. 481-510, 1985.

. The strength of weak ties. The American Journal of Sociology, v. 78, p. 1360-1380, 1973. . Where do social relations come from? A study of personal networks in the Toulouse area of France. Social Networks, v. 27, p. 289-300, 2005.

GROSSETTI, M. Sociologie de l'imprevisible. Dynamiques de l'activitéet des formes sociales. Paris: Presses Universitaires de France, 2004. 228p (Colletion Sociologie d'aujourd'hui).

GROSSETTI, M.; BES, M-P. Encastrements et découplages dans les relations science-industrie. Revue Française de Sociologie, v. 42, n. 2, p. 327-355, 2001. 
GROSSETTI, M.; BARTHE, J-F.; BESLAY, C. La mobilisation des relations sociales dans les processus de création d'enterprises. aperçus à partir d'une enquête en cours. Sociologies Pratiques, v. 13, p. 47-59, 2006.

LIMA, M.S.M. et al. Capacitação técnica vs comprometimento profissional: o real impacto do controle da hanseníase. Cad. Saúde Coletiva, Rio de Janeiro, v. 16, n. 2, p. 293-306, 2008.

LUZ, M T. Cultura contemporânea e medicinas alternativas: novos paradgmas em saúde no fim do século XX. Physis. Rev. Saúde Coletiva, Rio de Janeiro, v. 15, p. 145-176, 2005.

MARQUES, E.C. Redes sociais e pode no estado brasileiro. Aprendizados a partir das políticas urbanas. Rev. Brasileira de Ciências Sociais, Porto Alegre, p. 15-41, 2006.

MARSDEN, P.V. Core discussion networks of americans. American Sociological Review, v. 52, p. 122-131, 1987.

MERCKLE, P. Sociologiendes reseaux sociaux. Paris: La Découverte, Colletion Reperres, 2004. 121p.

MERHY, E.E. Em busca do tempo perdido: a micropolítica do trabalho vivo. In: MERHY, E.E.; ONOCKO, R. (Org.). Agir em saúde. São Paulo: Hucitec, 1997. P. 71-112.

MERHY, E.E.; IRIART, C.B.; WAITZKIN, H. Atenção gerenciada: da microdecisão corporativa à microdecisão administrativa, um caminho igualmente privatizante? Curso Managed Care e o Brasil do PROAHSA/HC/FGV, 1997. p. 29.

NEMES, M.I.B. et al. Adesão ao tratamento, acesso e qualidade da assistência em AIDS no Brasil, Revista da Associação Medica Brasileira, v. 55, n.2, p. 207-12, 2009.

NEUVILLE, J-P. La tentation oportuniste . Rev. Francaise de Sociologie, Paris, v. 39, n. 1, p. 71-103, 1998.

OLIVIERI, C. Política, burocracia e redes sociais: as nomeações para o alto escalão do Banco Central do Brasil. Rev. Sociologia Olitica, Curitiba, v. 29, p. 147-168, 2007.

RADOMSKY, G.; SCHINEIDER, S. Nas teias da Economia: o papel das redes sociais e da reciprocidadr nos processos locais de desenvolvimento. Sociedade e Estado, Brasilia, v. 22, n. 2, p. 249-285, 2007.

RAMOS JR, A.N. et al. Health System research training as a tool for more effective Hansen's diseases control programmes in Brazil. Leprosy Review, v. 77, p. 175-188, 2006.

ROSSONI, L.; HOCAYEN-DA-SILVA, A. J.; FERREIRA JUNIOR, I. Aspectos estruturais da cooperação entre pesquisadores no campo da administração pública e gestão social: análise das redes entre instituições no Brasil. Revista de Administração Púlica, Rio de Janeiro, v. 42, n. 6, p. 1041-1067, 2008.

SANTOS, A.M. et al. Linhas de tensões no processo de atendimento das equipes de saúde bucal do programa de saúde da família: o caso de alagoinhas, Bahia, Brasil. Cad. de Saúde Pública, Rio de Janeiro, v. 23, n. 1, p. 75-85, 2007. 
SLUZKI, C.E. A rede social na prática sistêmica. Trad. Claudia Berliner. 3 ed. Casa do Psicólogo, 1899. 145p.

STUFFLEBEAM, D. L. Evaluation models. San Francisco: Jossey-Bass, 2001. 107p.

VARANDA, M. Acção colectiva entre pequenos empresários:uma análise de redes sociais. Análise Social, v. 42, n. 182, p. 207-230, 2007.

WHITE, H.C.; BOORMAN, S A.; BREIGER, R.L. Social Structure from multiple networks. I. Blockmodels of roles and poditions. The American Journal of Sociology, v. 81, n. 4, p. $730-780,1976$. 
Social Network and Performance of Health Programs: an Investigative Proposal Major effort has been necessary to achieve decentralization of the health programs in Brazil, therefore essentially implying the creation of innovative practices. A number of researchers have been facing the challenge to carry on studies evaluating the implementation of health programs. Some ongoing research has been indicating interpersonal relations as an important factor, which explains the different consequences. This paper intends to discuss the importance of interpersonal relations in the implementation of health programs starting from the contribution of social network's analyses. Investigations towards the comprehension of performance variations in health programs which incorporate such outlook will be proposed.

> Key words: evaluation, health programs, social network, interpersonal relations. 